\section{Uber Adsorption von Elastase an synthetischem Natriumaluminiumsilikat}

BALo und BANGA ${ }^{1}$ haben im Jahre 1949 ein neues Enzym aus Rinderbauchspeicheldrüsen bekannt gemacht, das zu Abbau und Auflösung des spezifischen Eiweisses der elastischen Fasern aus der Aortawand fähig ist ${ }^{2}$. Die Verfasser haben die Extraktion und partielle Reinigung der neuen Pankreasprotease beschrieben und das Enzym "Elastase» benannt ${ }^{3}$. Im Jahre 1952 gelang es BANGA, ein kristallisiertes Enzympräparat durch Verwendung der klassischen Aussalzungsmethode darzustellen". Die nach BANGAS Verfahren hergestellte Elastase diente als brauchbares Ausgangsmaterial ${ }^{5}$ für viele Versuche. Das kristallisierte Enzym besass aber neben seinen Vorteilen auch nachteilige Eigenschaften. Die Ausbeute des kristallinischen Produktes war besonders ungünstig: es erreichte kaum 3-4\% der Enzymaktivität des Ausgangsmaterials.

In unseren Versuchen zur Reinigung und Isolierung von Elastase wurde die Asorption des Enzyms an verschiedenen Adsorptionsmitteln untersucht. Es wurde beobachtet, dass die Elastase sich aus schwach sauer wässriger Lösung an gewisse Adsorptionsmittel, zum Beispiel an aktivicrte Kohle oder verschiedene Zeolithe gut adsorbiert, in nur geringem Grade aber an Bentonit und saure Kunstharz-Austauscher. Im folgenden wird die Adsorption des Enzyms an synthetischem Zeolith beschrieben.

$100 \mathrm{~g}$ durch Azeton entfettetes und getrocknetes Pankreaspulver (Pankreatin Richter, Budapest) wurde in zwei Stufen mit insgesamt 2 Liter einer $0,1 \mathrm{M}$ Azetatpufferlösung von pH 4.7 extrahiert. Die Extraktion wurde bei Raumtemperatur nach Befeuchtung und Zerreibung des Organpulvers unter 1-2stündigem Rühron durchgeführt. Nach Abzentrifugieren der unlöslichen Organreste wurden die Extrakte vereinigt und durch ein hartes Faltenfilter filtriert. Die wasserklare, hellgelbliche Enzymlösung wurde nun mit einer Geschwindigkeit von 8 bis $10 \mathrm{~cm}^{3} / \mathrm{min}$ durch eine Säule aus synthetischem Natriumaluminiumsilikat filtriert. Die Kolonne hatte einen Durchmesser von $50 \mathrm{~mm}$, eine Höhe von 50 bis $60 \mathrm{~cm}$ und enthielt etwa $300 \mathrm{~g}$ Decalso (Permutit Co., London), das vorher mit einer $3 M$ Ammoniaklossung aktiviert worden war. Das überschüssige Ammoniak wurde vor Beginn der Adsorption durch $0,01 M$ Salzsäure entfernt und die Kolonne mit destillicrtem Wasser gewaschen. In der durch die Kolonne filtrierten Enzymlösung ist nur noch eine geringe Enzymaktivität nachweisbar. Die Adsorption hat einen Wirkungsgrad von $85-95 \%$. Die Kolonne wurde nach Beendigung des Adsorptionsprozesses mit einer $0,2 M$ Azetatpufferlösung von $\mathrm{pH} 4.7$ und mit destilliertem Wasser gewaschen.

Wir versuchten die Elution des Enzyms mit verschiedenen Lösungsmitteln und bei verschiedenen pHWerten. Die Abbildung zeigt den Zusammenhang zwischen den pH-Werten des Elutionsmittels und dor Aktivität der eluierten Elastase. Daraus geht klar hervor, dass die bei alkalischer Reaktion durchgeführte

1 J. Baló und I. Banga, Schweiz. Z. Path. Bakt, 12, 350 (1949).

2 J. Baló und I. BANGa, Biochem. J. 46, 384 (1950).

3 J. Baló und I. Banga, Nature 164, 491 (1949).

4. Banga, Acta physiol. hung. 3, 317 (1952).

5. A. HALL ind T. E. GARDINER, Biochem, T. 50,465 (1955),

S. M. Partridge und H. F. Davis, Biochem. J. 61, 21 (1955). -

L. RoBert und P. SAMuet, Exper. 13, 167 (1957).
Elution zu ungünstigen Resultaten führt, indem die Aktivität des Endprodultes beträchtlich abnimmt, obwohl keine Denaturierung stattfindet. Unter den zur Elution verwendeten Lösungsmitteln erwies sich eine $40-45 \%(V / V)$ wässrige Athyl- oder Methylalkohollösung, die 8-12\% Ammoniumazetat enthiclt, als das beste. Das Enzym wurde mit $600 \mathrm{~cm}^{3}$ dieser alkoholischen Salzlösung eluiert. Nacher wurde es aus dieser Lösung bei einet Temperatur von -2 bis $-6^{\circ} \mathrm{C}$ durch Zusatz des dreifachen Volumens absoluten Äthylalkohols ausgefällt. Der Niederschlag sedimentierte in einigen Stunden. Nach Absangen der klaren Lösung wurde der Nioderschlag im Kühlraum abzentrifugiert, danach in einer $0,01 M$ Azetatpufferlösung von pH 5.0 gelöst und das Enzym im gefrorenen Zustande getrocknet.

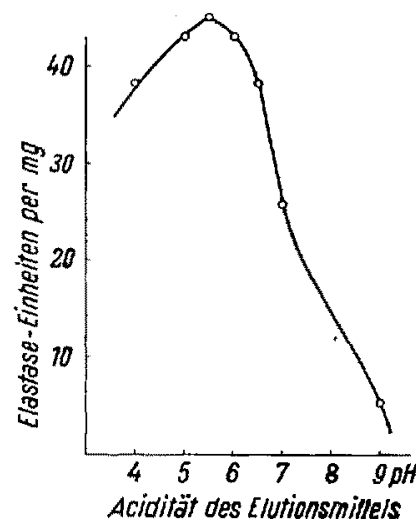

Aktivität der eluierten Elastase in Abhängigkeit von der Azidität des Elutionsmittels

Die durch die beschriebene Methode hergestellten Elastasepräparate enthielten $40-70$ E.E. (Elastase-Einheiten) pro mg. Sie übertreffen die Aktivität des kristallinischen Enzympräparates. Die Ausbeute des Adsorptionsverfahrens beträgt $30-50 \%$, ist also besser als bei den in der Literatur veröfentlichten Verfahren. Papierelektrophoretisch ist das Enzympräparat nicht homogen. Dies steht in Ubereinstimmung mit den früheren Angaben von HALL' Wir haben beobachtet, dass die Löslichkeit der einzelnen Komponenten, wie zum Beispicl jene der Elastomucoproteinase ${ }^{7}$, unter bestimmten Umständen verschieden ist. Auf dieser Basis ist ihre Isolierung im Gange.

Ausführliche Angaben werden in Acta physiol. hung. erscheinen.

D. BAGDY und I. BANGA

Forschungsinstitut für Pharm. Industrie, Budapest und I. Institut für Pathologische Anatomie und Experimentelle Krebsforschung der Medizinischen Universitat, Budapest, den 2. Mai 1957.

\section{Summary}

We have described an adsorption method for the isolation of elastase. With this method, the yield of the enzyme is better and the purity is greater than with the methods described previously.

6 D. A. Halc, Biochem. J. 55, 25 (1953).

7 I. BANGA und J. BALo, Nature 178,310 (1956), 